tunidad y que, además, ha servido de nombre a la editorial. Así, este pequeño gesto es en realidad una muestra de que nada en este libro, ni siquiera el guiño verde en la solapa posterior, ha sido librado al azar.

Como medievalistas, no queda sino celebrar esta primera publicación del equipo de traductores coordinado por
A. Tursi, deseando que continúen su labor y no permitan que a la decepción de Petrarca por no leer más de Lotario (p. 14), se le sume la nuestra por no leer más de ellos.

NATALIA JAKUBECKI

$U B A$

CONICET

\title{
Ricardo Gutiérrez Aguilar, Deuda y legado de la Filosofía de la Historia de Schiller, Barcelona, Herder, 2018, 432 pp.
}

A los efectos de enmarcar el propuesta de su autor ha de señalarse que el 26 de mayo de 1789 Schiller pronuncia en Jena su Lección inaugural como docente titulada: ¿Qué viene a significar y para qué se estudia Historia Universal? En esta época, Schiller está leyendo de Kant Ideas para una historia universal en clave cosmopolita y responde a las posiciones de este último. En este marco su Lección analiza dos aspectos centrales: la fuente documental y al propio historiador que la interpreta. Con respecto a las fuentes defiende la misma causalidad que la Naturaleza le garantiza a la Ciencia. En cuanto al oficio del historiador, sus tópicos centrales son la motivación y el reino de la Libertad. De este modo, cientificidad y estética confluyen en el análisis schilleriano de la historia. Con este hilo conductor despliega Ricardo Gutiérrez Aguilar su análisis de la Filosofia de la Historia de Schiller. Ya desde la introducción del libro señala la importancia que tiene el pasado y la posibilidad de su recuperación (pp. 11-14). El objeto de este extenso y erudito estudio es presentar al lector los dos conceptos centrales que vertebran el análisis: el documento-fuente historiográfica y la interpretación del historiador (p. 15). En lo que sigue analizamos esta doble articulación en las cuatro partes en que se divide el libro.

En la primera parte se reconstruyen los tópicos de la lección inaugural de Schiller en la cual se destaca su análisis del progreso (p. 30). A partir de aquí el vínculo con Kant es presentado por el autor siguiendo el hilo conductor de la noción de gratitud (pp. 31-38). En la sección 1.1. se profundiza esta comparación entre ambas filosofias de la historia. Es así como Schiller desarrolla en su Lección inaugural los principios normativos y descriptivos en la historia y la 
analogía como método (p. 51, 67 y ss.). Paralelamente, se destaca la importancia que el mundo moral reviste para la ciencia histórica según Kant (pp. 71-74). La sección se cierra con una destacada reconstrucción de la contraposición schilleriana entre el Historiador Universal que hace un uso correcto de la analogía, según explica la teleología schilleriana, y el "ganapán (Brotgelehrte)" o académico a sueldo que trabaja temas históricos como un oficio para vivir (pp. 83-100), reconstrucción motivada en una anécdota que describe cómo Schiller, dos semanas antes del dictado de su Lección, entró en contacto con la población que lo habría de escuchar (p. 78).

En la segunda parte se comparan las posiciones de Kant y Schiller mostrándose algunas semejanzas: “... donde no teníamos dificultades para ver en la fisionomía de la 'cabeza filosófica' al historiador universal, ahora no hemos de tener ninguna en identificar certeramente los rasgos del 'historiador empírico' en la faz del académico a sueldo” (p. 103). El análisis (hasta p. 138) permite evaluar entre otros aspectos nuevamente la función estructurante del método de analogía (p. 110) que será continuada en la sección siguiente II.1. Ella analiza el papel de la expectativa fundamentando su análisis en un recorrido riguroso por el estoicismo clásico (pp. 139-149). Este examen oficia de introducción al estudio de la relación entre historia y filosofía moral en el pensamiento de Kant. En este marco, Gutiérrez Aguilar presenta las tres desviaciones a la noción de expectativa analizadas por Kant: el terrorismo moral o eudeimonismo, el quiliasmo y el abderitismo (pp. 155-162). Las páginas finales de esta sección se cierran con un relevante análisis de la noción de "revolución de un pueblo pletórico de espíritu” (p. 167), tema gracias al cual se contraponen las posiciones filosóficas sobre historia de Kant y Schiller, culminando con la pregunta: “¿Qué representa objetivamente pues la revolución?” (p.168).

En la tercera parte, el autor contrapone, por medio del hugonote francés Pierre Coste, las posiciones filosóficas de Leibniz y Locke hacia 1707 y repone sus discusiones con Shaftesbury (pp. 187-205). Destaca en este análisis la posición de Schiller: "Leibniz no podría soñar con mejor acomodo que el texto de Schiller. Pero Schiller se ha interesado antes por Shaftesbury que por Leibniz" (p. 222). En la sección III.2. resulta relevante cómo el autor reconstruye influencias muy importantes en el joven Schiller: la de Kant con su noción de experiencia estética (pp. 235-237); las trasmitidas por Jakob Friedrich Abel del Stif de Tubinga (p. 240), la Popularphilosophie (pp. 241-243); la de Locke (pp. 243-244); la teoría del sentimiento moral y la escuela del sentido común (p. 245); las de Rousseau y Shakespeare (pp. 247-248); Klopstock, Goethe y Herder (p. 248) y, finalmente, las ciencias naturales y la psicología (p. 249). En las páginas finales de la sección se recupera la noción de Historia Universal de Schiller (pp. 252-258) señalando su atributo de fragmentariedad (p. 252) y su avance desde historiador poético a observador filosófico (p. 258).

La sección III.3 recuerda que Schiller se ha rencontrado en Weimar con sus sentimientos de juventud, a raíz de ello se repone la anécdota de su encuentro en Jena con el modelo de pensador kantiano, Reinhold, encuentro en el cual Schiller descubre que nunca podría ser su amigo (pp. 258-260). La anécdota da lugar a una extendida reflexión sobre la influencia de la filosofía trascendental 
y moral kantiana en la filosofia de la historia de Schiller y el debate entre ambos autores (pp. 261-295) hasta su "armisticio" (p. 288). Destaca en esta contraposición la noción kantiana de Historia como narración de las acciones morales humanas (p. 267), y la importancia del sentimiento, de los afectos y de la sensibilidad en el diálogo schilleriano con Kant (pp. 280, 287).

Aquí encontramos la importancia que para Schiller reviste el juicio estético, el cual solo aparentemente puede tener un carácter contradictorio con la ética (p. 293). Por este camino, que reconoce la importancia del sentimiento en la Historia, llegamos al "patrón Montesquieu” (p. 297) en su L'espirit des lois, analizando cómo los impulsos positivos y las pasiones son motores que dan lugar a los gobiernos (p. 295). El autor recuerda que para Schiller libertad y necesidad se limitan mutuamente, deber y querer son reinos vecinos que se disputan su supremacía en el campo de batalla del individuo (p. 298). Por ello retoma el hilo conductor de Kant y Schiller como autores que se han leído mutuamente (pp. 298-309). En especial, resulta interesante cómo Schiller concede gustoso la majestuosidad de la reflexión kantiana sobre la ley moral y la noción de "respeto" (pp. 301 y ss.). Se presenta aquí la diferencia fundamental entre ellos: la teleología "como analogía de la moral" no es válida para Schiller, pues para él la moral no es una categoría explicativa primera y por lo tanto es posible otra teleología y otra Filosofia de la Historia (p. 309).

En la cuarta y última parte, en la primera sección IV.1., destaca la indagación de la noción schilleriana de verdad como una relación directa entre expresión y sentimiento en el juicio (p. 314). Para Schiller es posible que dos supues- tos irreconciliables se relacionen, la historia puede ser discontinua y casual, es posible una relación no accidental entre un hecho y un modo de pensar, entre un sentimiento y su expresión, entre el reino de la necesidad y el de la libertad ( $\mathrm{p}$. 321). La sección IV.2. retoma la contraposición entre Naturaleza e Historia. La naturaleza, para Kant, es generosa y hay que elegir entre cultura y felicidad, entre virtud y felicidad (p. 335); en cambio, para Schiller, la naturaleza contiene todo lo que la felicidad comprende y la cultura consiste en aquello que el ser humano puede ofrecer o tomar de ella (p. 336).

A partir de aquí Gutiérrez Aguilar realza el valor de la noción de Historia Universal en ambos autores. Para Schiller, la Historia Universal se sitúa al comienzo del mundo y las consecuencias efectivas de todos esos sucesos desciende desde el origen hasta su orden más reciente (p. 342). El autor señala una fundamental contraposición: mientras que para Kant la Historia Universal que nos ofrece Schiller es un mero agregado de fragmentos y no puede ser una ciencia, para Schiller la historia no es sino el comienzo del mundo porque a partir de ella se empieza con el documento y la fuente; si el historiador destaca ciertos acontecimientos es porque han ejercido una influencia esencial en la configuración actual del mundo (p. 347). Por ende, la fragmentariedad es un atributo de la Historia Universal para Schiller, pero no por eso es menos verdadera (p. 348).

Con una reflexión sobre la naturaleza, la necesidad y el acto de voluntad (pp. 363-366) llegamos a la tercera y última sección IV.3. Como indica el autor: "Se abre el fértil vergel que es el campo de la Historia Universal a la observación del caminante reflexivo..." (p. 366). La sección esboza, a modo de 
conclusión, las menciones al tratamiento kantiano de la imaginación (pp. 386 y ss.) y la referencia a Schiller: "Si para Schiller la libertad es la posibilidad de tornar lo necesario en contingente, de reclamar un derecho sustraído injustamente, se entiende nuestro afán en que la imaginación explique su dinámica aquí a la perfección” (pp. 388-389). Estas palabras permiten comprender el legado que, a juicio de Gutiérrez Aguilar, nos deja Schiller: la historia es una ciencia que pretende ser una estética objetiva, una ciencia que dé cuenta del porqué del agrado y del desagrado, del placer y el displacer, una ciencia que sería totalmente imposible para Kant (p. 392). Una ciencia de estas características llevaría al tratamiento de la belleza como una libertad de aparición: esa libertad sería un derecho instituido. De este modo, la historia deviene una estética objetiva que complementa a la subjetiva (p. 393).

Deuda y legado de la Filosofía de la Historia de Schiller es un libro que posee densidad conceptual acompañada de una cuidada y bella prosa que invita al lector a demorarse en las descripciones y debates epocales que se reponen. Se trata de un estudio fundamental, indispensable para especialistas en filosofia de la historia que quieran actualizarse en la obra schilleriana y para aquellos que no la conocen permite adentrarse en la profundidad y complejidad de su pensamiento sobre la historia, en sus aportes indudables, pero también su deuda, entendiendo por esta el diálogo de su filosofia en el contexto de su tiempo con sus interlocutores, en especial, con la obra de Immanuel Kant.

MARIO GÓMEZ

$U B A$

\section{Johann Georg Hamann, Memorabilia Socratica / Nubes, traducción y notas de Miguel Alberti y Florencia Sannders, Los Polvorines, Universidad Nacional de General Sarmiento, 2018, 315 pp.}

М $\begin{aligned} & \text { iguel Alberti y Florencia } \\ & \text { Sannders ofrecen esta cui- }\end{aligned}$ dada edición de Memorabilia Socratica y Nubes de Johann Georg Hamann. Tanto el texto, bilingüe alemán-español, como el extenso número de notas se encuentran justificados. Por un lado, contar con el texto alemán permite a los lectores seguir la prosa original, las citas de la Biblia de Lutero y ubicar los conceptos clave. Por el otro, las abundantes notas de los traductores, que se ofrecen al final del texto, pueden hacernos tomar un camino alternativo, en el cual la lectura del alemán no es imprescindible. Los ensayos de Hamann se caracterizan por contener innumerables referencias eruditas, ya sea a la Biblia, a su propia concepción filosófica, a la historia o a filosofias contemporáneas al autor, por 